\title{
Quando as mulheres transgridem o espaço: João Guimarães Rosa e Graciliano Ramos em comparação
}

\author{
When women transgress space: Comparing \\ João Guimarães Rosa and Graciliano Ramos \\ Sandra Sousa \\ University of Central Florida - UCF - Orlando - Estados Unidos
}

\begin{abstract}
Resumo: Este estudo procura ser uma contribuição para a análise do género nas obras de dois dos autores mais relevantes da literatura brasileira do século XX, Graciliano Ramos e João Guimarães Rosa. Procura-se desmantelar, através da teoria do espaço, a ideologia de género que subjaz a São Bernardo e Buriti. Pretende-se igualmente verificar a ocorrência de dissonâncias no tratamento das personagens femininas nos dois autores. Procura-se, finalmente, contribuir para uma reavaliação da construção da feminilidade nas obras, construção essa que não é de forma nenhuma independente das visões que os autores tinham da sociedade da sua época.
\end{abstract}

Palavras-chave: Literatura Brasileira. Espaço. Género Feminino.

Abstract: This study aims to contribute to the analysis of gender in the works of two of the most relevant authors in twentieth-century Brazilian literature, Graciliano Ramos and João Guimarães Rosa. Employing the theory of space, I unpack the gender ideology that underlies São Bernardo and Buriti. My essay also seeks to verify the occurrence of dissonances in the treatment of female characters in both authors. Ultimately I offer a reassessment of the construction of femininity in the works-a construction which is in no way independent of the views that each author had of the society of his time.

Keywords: Brazilian Literature. Space. Feminine gender. 


\section{Dois autores, três mulheres}

A extensa literatura crítica que existe à volta de Graciliano Ramos e João Guimarães Rosa se, por um lado, parece afirmar que tudo está dito e resolvido, por outro, apresenta provas da inesgotabilidade da obra destes. Citando apenas dois exemplos, Allan Englekirk afirma que "The fictional world created by João Guimarães Rosa was quite unique to the pages of Brazilian literature" (1982, p. 52) e Godofredo Neto, comentando acerca de Graciliano Ramos refere que "é inegável a importância do conjunto da [sua] obra para a cultura brasileira" (1990, p. 13). São estes dois argumentos, unicidade e importância, que se apresentam como um desafio e obrigam a que nenhum mero leitor/crítico consiga contorná-los. É devido a esta incontornabilidade que aqui se apresentará mais uma proposta de análise destes dois escritores. Tem-se, assim, como intenção contribuir para uma avaliação do modo como estes dois escritores refletem ou não uma visão do feminino dentro dos parâmetros estabelecidos do patriarcado.

Grande parte da crítica graciliana aponta essencialmente para uma abordagem de São Bernardo como uma obra ideológica e de protesto social, além do seu carácter psicológico. A respeito do conjunto de contos que Rosa intitulou Corpo de Baile, Jon S. Vincent afirma que este livro contém "some of the most 'difficult' and at the same time some of the most rewarding fictional experience in modern literature" (1977, p. 98). Contudo, e apesar de vários pesquisadores terem já elaborado trabalhos de excelência sobre a figura feminina em ambos os autores, nenhum estudo existe que faça uma comparação entre os dois na forma de tratamento das mulheres que povoam as suas obras. Neste trabalho propõe-se, por conseguinte, não apenas uma comparação entre Graciliano Ramos e Guimarães Rosa, mas também verificar se existe, a respeito do tratamento da personagem feminina, alguma dissidência de um pensamento para o outro, tendo em vista a forma como a mulher nas suas obras se move num espaço que, de acordo com a sua classe social, a relega para os limites do doméstico.
De acordo com Susan Rubin Suleiman, "Women, (...) for centuries had been the objects of male theorizing, male desires, male fears and male representations" (1985, p. 43) a que se poderia ainda acrescentar, objectos da organização espacial masculina. Neste sentido, levanta-se a questão: procedem tanto Rosa como Ramos a tal objectificação de Madalena, Maria da Glória e Leandra, ou serão estas duas grandes figuras da literatura brasileira inovadoras a esse respeito?

Sabemos que a Literatura Brasileira estava confinada a um paradigma tradicional e europeu em que "a polaridade homem/mulher e masculino/feminino era tida como inerente às características universais da "natureza" humana, assim como através dela se podia "explicar" e ter por naturais e universais as relações de dependência e de opressão" (HELENA, 1989, p. 44). É tendo em conta esta dependência e relação desigual de poder caracterizadora, não só de um sistema social, como também das relações entre sexos assentes num sistema de patriarcado, que se pretende averiguar se, tanto em São Bernardo como em Buriti, os narradores se limitam a uma representação da mulher segundo as regras vigentes ou, se por outro lado, existe uma transgressão em relação ao papel da personagem feminina. Pretende-se ainda averiguar se existe uma cisão, visto uma obra ser contemporânea da outra, no tratamento da figura feminina, ou se, pelo contrário, os parâmetros são os mesmos. Através de uma teoria do espaço, procuro analisar o modo como as personagens femininas, que poderão ser designadas de "mulheres do sertão," se posicionam em relação a espaços caracteristicamente dominados pelo masculino. Associada à questão do espaço como elemento estruturante na definição de relações de poder, podem ainda acrescentar-se as noções de corpo e sexualidade femininos, na medida em que levantam questões que no seu conjunto têm "implications both for politics - that is, for the relations of power and control that govern a society-and for literature, or the production of verbal constructs that in some ways reflect and in some ways help to create those relationships" (SULEIMAN, 1985, p. 43). 


\section{Espaço Constituidor do Género}

O pensamento feminista tem vindo, ao longo das últimas décadas, a debruçar-se sobre as formas como o espaço social e geográfico constrói relações de poder que estão na base das culturas patriarcais e como esse modo de organização espacial contribui para a relação entre os sexos. É interessante verificar, através das obras de Ramos e Rosa, que na sociedade brasileira do século XX existe ainda uma divisão social do espaço que estabelece fronteiras dialéticas entre o público (associado ao masculino) e o privado (associado ao feminino), contribuindo para uma relação específica entre homens e mulheres. Uma vez que os géneros estão demarcados em certos espaços sociais, estas obras revelam-nos algo acerca das relações entre personagens masculinas e femininas, ao comentarem e descreverem o modo como a sociedade desta altura se configura espacialmente. Se, por um lado, temos a cidade e o campo (sertão) associados a regras sociais divergentes, por outro lado, cada um destes espaços constitui-se a partir das suas próprias normas.

A organização do espaço é, hoje em dia, vista, a par de outros sistemas de comunicação, como uma linguagem em si, também ela transmissora de ideias sobre autoridade e privilégio. Segundo Elizabeth Keating, "The distribution of space can instantiate particular systems of social control, for example, conventionalizing differences between people, and making such delineations material and substantive, as well as anchoring them within historical practice" ( $p$. 234). Deste modo, o conjunto de regras sociais inerentes a um determinado espaço, as fronteiras que esses espaços ditam, são muito mais importantes do que parecem à primeira vista, para se entender 0 significado do que é ser homem ou mulher numa determinada sociedade. Como afirma Linda McDowell,

These two aspects-gender as a set of material social relations and as a symbolic meaning — cannot really be separated-(...) it is clear that social practices...and ways of thinking about and representing place/gender are interconnected and mutually constituted. We all act in relation to our intentions and beliefs, which are always culturally shaped and historically and spatially positioned. (1999, p. 7)

Mulheres e homens vivenciam os espaços e os lugares diferentemente e estas diferenças são elas próprias parte de uma constituição social de género, assim como de espaço. Ainda segundo a mesma autora:

(...) spatial division-that between the public and the private, between inside and outside-plays such a central role in the social construction of gender divisions. The idea that women have a particular place is the basis not only of the social organization of a whole range of institutions from family to the workplace, from the shopping mall to political institutions, but also is an essential feature of Western Enlightenment thought. (1999, p. 12)

A forma como diferentes espaços são vivenciados varia de mulheres para homens, adquirindo, diferentes significados e diferentes relações de poder. Os espaços que se configuram de liberdade para uns podem muito bem assumir formas de perigo para outros, tendo de ser evitados. Deste modo, Sandra Graham afirma que, "Fundamental to the order and meaning of daily, domestic life were the categories of casa and rua, house and street. House represented private and protected spaces that contrasted with the public and unpleasant, possibly dangerous places of the street" (1988, p. 15). Assim sendo, Madalena, a figura feminina de São Bernardo, Maria da Glória e Leandra, personagens de Buriti, como mulheres de classe social mais elevada (casada com fazendeiro, filha e nora de fazendeiro, respetivamente) supostamente deviam contribuir para a perpetuação de uma ordem social patriarcal em que elas mesmas se inserem, permanecendo no espaço que Ihes estava reservado. Elas são mulheres que vivem num espaço dividido socialmente, não só em termos de campo/cidade, mas fundamentalmente no próprio espaço da fazenda sertaneja, em que à mulher (como esposa ou família do fazendeiro) estava interdita a circulação livre pela propriedade e o relacionamento com os subalternos do fazendeiro e, por conseguinte, também seus. Como se irá observar, as três personagens em questão não se comportam de acordo com as regras sociais inferidas do espaço que lhes é destinado no sistema em que se inserem. 
No que diz respeito a estas "mulheres do sertão" a dicotomia cidade/campo irá ter, igualmente, relevância fundamental na forma como estas personagens se configuram em relação ao seu próprio corpo, sexualidade e ação social.

\section{Madalena, a transgressora social}

É conhecida a "história de amor" em São Bernardo. Paulo Honório e Madalena configuram-se como um dos pares amorosos literários mais instigantes para quem tem como intenção perceber o papel da mulher dentro de sistemas designados de patriarcais. Neste tipo de sistema, o homem como proprietário de terras tem, não apenas o poder sobre os seus subalternos que trabalham a terra e tratam da criação de animais, mas também o poder sobre a mulher. Esta era-lhe dependente e devia-lhe submissão, além de ter o papel de progenitora, perpetuando, desta forma, o sistema vigente.

Neste sentido, é Madalena sempre uma figura subordinada ou estará o nosso pensamento já viciado e só conseguimos ver o que as nossas ideias préconcebidas nos obrigam a ver? Na opinião de Richard A. Mazzara a falha imperdoável de Madalena "is her neglect of the son she has borne Paulo Honório" (1968, p. 95). Contudo, poderá o leitor perdoá-la se a entender? É na observação do percurso espacial da co-protagonista do romance que pretendo uma possível explicação para as questões levantadas.

O retrato que nos é oferecido de Madalena pelo narrador, segundo Lúcia Vianna, é a de uma mulher "Bonita, culta, educada, moça direita, de bons costumes, delicada e boa" (1997, p. 68), a que poderíamos acrescentar a, não menos importante característica, de mulher citadina. Como mulher da cidade e exercendo a profissão de professora, poderíamos ser levados a pensar que Madalena nunca trocaria a sua vida de liberdade burguesa por uma de enclausuramento no campo. No entanto, a sua situação económica leva-a a tomar a decisão de casar e mudar-se para a fazenda de Paulo Honório. Desde logo, torna-se evidente que na decisão de casar o amor não entra como condição irrevogável; pelo contrário, o casamento é visto como um negócio, não apenas pelo narrador materialista, mas também pela própria Madalena. Atente-se numa parte da conversa entre Honório e Madalena quando este lhe propõe casamento:

-O seu oferecimento é vantajoso para mim, Seu Paulo Honório-murmurou Madalena. -Muito vantajoso. Mas é preciso reflectir. De qualquer maneira, estou agradecida ao senhor, ouviu? A verdade é que sou pobre como Job, entende?

-Não fale assim, menina. E a instrução, a sua pessoa, isso não vale nada? Quer que eu Ihe diga? Se chegarmos a acordo, quem faz um negócio supimpa sou eu. (RAMOS, s/d, p. 56)

Este diálogo deixaria qualquer romântico perplexo. No entanto, a crueza e realismo nele contidos revela a materialidade das relações conjugais antes de se ter inventado a ficção do amor no casamento. Até há bem pouco tempo na história da humanidade, o casamento não tinha o termo "amor" como uma das suas vertentes. De acordo com Marc Shell, um dos pensadores que se tem ocupado em demonstrar a relação entre a teoria literária e a teoria e produção económicas,

This participation of economic form in literature and philosophy, even in discourse about truth, is defined neither by what literature and philosophy talk about (sometimes money, sometimes not) nor by why they talk about it (sometimes for money, sometimes not) but rather by the tropic interaction between economic and linguistic symbolization and production. A formal money of the mind informs all discourse and is as unaffected by whether or not the thematic content of a particular work includes money as by whether or not the material content of the ink in which the work may be inscribed includes gold. (1993, p. 4)

Como se pode depreender, não é apenas o discurso de Paulo Honório que é informado pelo tropo "money of the mind," o discurso de Madalena é também moldado economicamente. Madalena é, por conseguinte, uma personagem feminina singular, pois a sua visão da vida não é atrapalhada pelos romantismos, muitas vezes, piegas a que nos habituaram outras heroínas literárias do século XIX. Se se pode argumentar que Paulo Honório transforma Madalena e "os outros em coisas, ou, no máximo que conseguia, em bichos" (NETO, 1990, p. 65), o mesmo se pode afirmar de Madalena em relação a Honório. A seguinte passagem o confirma: 
-Parece que nos entendemos. Sempre desejei viver no campo, acordar cedo, cuidar de um jardim. Há lá um jardim, não? Mas porque não espera mais um pouco? Para ser franca, não sinto amor.

-Ora essa! Se a senhora dissesse que sentia isso, eu não acreditava. E não gosto de gente que se apaixona e toma resoluções às cegas. (RAMOS, s/d, p. 58)

Madalena é uma personagem prática para quem a segurança económica se sobrepõe ao amor. Ela não é "o tipo de leitora burguesa," entregue a devaneios que pusessem em risco a estabilidade conjugal" (VIANNA, 1997, p. 70). A sua decisão de mudar de um espaço citadino para um campestre é uma decisão objetiva, contudo, como veremos, esta transferência vai ter um preço a ser pago.

Quando começam a viver em São Bernardo como um casal, as diferenças entre Honório e Madalena começam a evidenciar-se. $\mathrm{Na}$ fazenda existe uma divisão de espaço que terá um papel fundamental na forma como o género é construído na obra. É interessante verificar que, para Paulo Honório, há uma distinção entre trabalhos femininos e masculinos e uma fronteira entre espaços destinados a homens e mulheres. Para o narrador, esta fronteira jamais deve ser ultrapassada. Contudo, assim que Madalena se instala, começa desde logo a infringir as regras estabelecidas por Honório no São Bernardo. O seguinte excerto é disso exemplo:

-Mas gostou de Seu Ribeiro: meteu-se no escritório, folheou os livros, examinou documentos, desarmou a máquina de escrever, que ainda estava emperrada. $E$ dois dias depois do casamento, ainda com um ar machucado, largou-se para o campo e rasgou a roupa nos garranchos do algodão. À hora do jantar encontrei-a no descaroçador, conversando com o maquinista.

-Ora muito bem. Isto é mulher.

Mas aconselhei-a a não expor-se:

-Esses caboclos são uns brutos. Quer trabalhar? Combino. Trabalhe com Maria das Dores. A gente da lavoura só comigo.

-A ocupação de Maria das Dores não me agrada. Eu não vim para aqui dormir. (p. 59)

A personalidade de Madalena começa, a partir daqui, a acentuar-se e nota-se como o seu primeiro impulso é de rebeldia, de não se querer deixar submeter a Honório. Nesta passagem destaca-se o início da luta de forças entre o narrador e Madalena. De facto, ela não se confina às regras estabelecidas pelo marido, ou seja, de que se deveria restringir ao espaço da casa e às atividades domésticas, não devendo estabelecer relações com os subalternos, e continua a invadir um espaço que pela lei do marido não Ihe está reservado. Madalena invade todas as partes da fazenda, inclusive a casa dos subordinados de Honório, oferecendo-lhes prendas e tentando proporcionar-lhes uma vida melhor. Honório tenta ainda modificá-la, ter controlo sobre ela, mas esta vai ser uma disputa levada ao extremo, que culminará na morte de Madalena. Atente-se na passagem que se segue:

Aí eu [Paulo Honório] peguei a xícara de café e amoleci:

—Não, assim também não. Para que exagerar? Incompreensão é o termo. Eu explico. Aqui não é como lá fora. O cinema, o bar, os convites, a lotaria, o bilhar, o diabo, não temos nada disso, e às vezes nem sabemos como gastar o dinheiro. Quer que Ihe diga? Comecei a vida com cem mil réis alheios. . .

Madalena ouviu atenta, aprovando, com modos de menina bem-educada:

- Acredita, acredito. O que há é que ainda não conheço o meio. Preciso acostumar-me. (p. 64)

Apesar da evidente diferença de linguagem a que tanto Honório como Madalena recorrem, e da demarcação também ela estampada da diferença entre o espaço da cidade e o do campo, o que sobressai deste episódio é o facto de Madalena parecer querer demonstrar subordinação. No entanto, percebemos nas palavras de Honório uma ironia quando se refere aos "modos de menina bemeducada." Ele sabe, e nós também, que Madalena está a ser dissimulada, que está apenas a tentar enfraquecê-lo com os seus bons "modos," ou seja, a evitar um conflito aberto. Sabemos ainda que ela não tem intenções de se acostumar, muito pelo contrário, as suas ações futuras comprovam a sua rebeldia, inconformismo e tentativa de mudança.

A irreverência de Madalena é igualmente visível no facto de querer ter um ordenado pelo seu trabalho de organização e escrita da correspondência de Honório: "-Faça a correspondência. Quer ordenado. Perfeitamente, depois combinaremos isso. Seu Ribeiro que lhe abra uma conta" (p. 65). É assim que, mesmo no limite do espaço da casa, Madalena 
consegue infringir as regras, não se dedicando a atividades relacionadas com o feminino, conquistando mesmo alguma flexibilidade por parte de Honório.

Voltando a uma das questões colocadas, acerca da negligência de Madalena do seu filho, aspeto que Mazzara aponta como a única culpa da mesma, convém lembrar-nos que o sentimento de maternidade que naturalmente é atribuído à mulher, não passa de uma construção social. Nada em Madalena nos indica que ela tem essa necessidade primordial. Pelo contrário, a sua predisposição parece ser muito mais para o trabalho, a ajuda humanitária, a literatura e a política. Na verdade, o tempo de gravidez encontra-se omitido do romance assim como a opinião de Madalena em relação à maternidade. Sabemos, sim, que Honório queria um filho, mas o próprio narrador é igualmente, se não mais, negligente em relação à criança. Esta está tão ausente do romance que quase nos esquecemos dela, a sua única finalidade parece ser a de proporcionar a continuação hereditária. Não se pode culpar Madalena de negligenciar o filho, se não temos acesso aos seus desejos mais íntimos, nem sequer ao modo de como encara a sua sexualidade (na verdade, nem sequer se pode confiar totalmente em Honório; como saber se ele não omite essa questão propositamente?). Esta parte de Madalena é-nos completamente estranha. Ao silenciar a sexualidade da personagem feminina, o narrador não está mais que a estabelecer uma ordem de poder, em que se verifica que a mulher não é mais do que um objeto, sem desejos e sem o controlo do seu próprio corpo. Madalena é usada para fins progenitores e a escolha de ser mãe não parece ser uma escolha sua. Aliás, sabemos de antemão o que Paulo Honório pretende ao casar: uma mulher que lhe dê um filho, que permita a continuidade do sistema que Honório simboliza:

Amanheci um dia pensando em casar. Foi uma ideia que me veio sem que nenhum rabode-saia a provocasse. Não me ocupo com amores, devem ter notado, se sempre que pareceu que mulher é um bicho esquisito, difícil de governar.

(...)

Não me sentia, pois, inclinado para nenhuma:

o que sentia era desejo de preparar um herdeiro para as terras de São Bernardo. (p. 38)

Na continuação da narração de Honório, temos a confirmação de que Madalena jamais Ihe será subordinada. Como se pode observar no excerto abaixo, Madalena continua a invadir o espaço proibido pelo marido e a ter contacto com os subordinados:

E mestre Caetano, gemendo no catre, recebia todas as semanas um dinheirão de Madalena. Sim senhor, uma panqueca. Visitas, remédios da farmácia galinhas.

-Não há nada como ser entrevado.

Necessitava, é claro, mas se eu fosse sustentar os necessitados, arrasava-me.

Além de tudo, vestido de seda para a Rosa, sapatos e lençóis para a Margarida. Sem me consultar. Já viram descaramento assim? (p. 74; ênfase minha)

Como se pode depreender, a proibição de Madalena andar por certos espaços-, não está apenas ligada a questões de género, mas igualmente à forma como o género interatua com a classe social, ou seja, Madalena, como mulher de fazendeiro, não deve imiscuir-se com a classe inferior e subalterna.

A insubordinação de Madalena, além de provocar ciúmes incontrolados e descabidos em Honório, levando-o à quase loucura, tem como única solução possível a morte. O suicídio da coprotagonista pode ser encarado como uma forma de libertação de uma situação que a pretendia presa a um espaço limitado. Num outro ponto de vista, esta morte pode também ser sinónimo de um preço a pagar pela infração desses espaços proibidos. E, se se pode ver na sua morte a perda da luta contra o sistema patriarcal, o inverso também é verdade, uma vez que Madalena teve um impacto e ofereceu a Honório um lado humano: a prova é o livro. De acordo com Sovereign, "In São Bernardo, brutality is openly expressed by Paulo Honório toward Magdalena, his wife, to the point where, at her suicide, it is clear that her husband was as guilty of murder as if he had handed her the fatal poison" (1970, p. 58). Ao "darIhe" o veneno fatal, Honório acaba por perder segundo as regras do seu próprio jogo, pois, teve de eliminar o ser superior para o supostamente vencer. Tal como Emma Bovary, do autor francês Gustave Flaubert, "having been created or seen by a male 
point of view, [Madalena] herself, a woman, is not allowed to become a point of view that sees and shapes reality, who sees or fashions man from her own point of view as a woman (according to her own desires)" (GINSBURG, 1995, p. 64).

São Bernardo apresenta-nos, deste modo, a visão de uma mulher que pretende um espaço próprio em que se possa constituir como sujeito. No entanto, a sua realização não é total, uma vez que, não nos podemos esquecer, só a podemos conhecer através de uma perspetiva masculina. A co-protagonista não se enquadra já, contudo, nos padrões da mulher submissa, controlada e sem vontade própria perpetuada por uma sociedade dominada pelo masculino. Madalena surpreende pelo facto de questionar não só os limites do espaço masculino/feminino, como a estrutura social subalternos/fazendeiros.

\section{Glória e Lalinha, as transgressoras sexuais}

Heloisa Vilhena de Araújo faz uso da mitologia grega para falar das personagens femininas de "Buriri," comparando, deste modo, Lalinha e Glorinha a ninfas. Refere a autora, "Lala e Glorinha são ninfas, flores à beira do brejo, à beira do pecado-"ócio e vício"-, ainda retidas, mas a ponto de dar-se" (1992, p. 144). Na mesma linha de pensamento, Wendel Santos aborda também estas personagens no seu sentido mítico, afirmando que:

Cada figura do Buriti Bom, com efeito, tem um carácter mítico: Zequiel é o oráculo da noite; Behú é, ao mesmo tempo, Anteros e Tânatos; e Lalinha é o símbolo da capacidade renovadora de Eros; Miguel é Narciso, e Glorinha, Vénus e Diana. Por outro lado, uma leitura comum nada mais vê em Zequiel a não ser o doido, em Behú a não ser a solteirona frustrada, em Lalinha a mulher vaidosa que se quer desejada, em Glorinha a moça ingénua que se deixa levar pelo velho glutão, e, em Miguel, o rapaz tímido. (1978, p. 52)

Embora interpretações válidas, não penso que seja preciso encarar estas personagens ao nível da mitologia para se ter uma ideia da complexidade do género em Guimarães Rosa, uma "leitura comum" será o suficiente para nos dar uma noção do que está em causa. Por outro lado, em termos de questões de género, Rosa parece estar muito mais preocupado com a forma como homens e mulheres entendem e revelam a sua sexualidade do que com os seus "pares" inalcançáveis do mundo superior.

$\mathrm{Na}$ mesma linha de análise que aqui tem vindo a ser discutida, pretende-se tentar compreender este complexo universo feminino que Guimarães Rosa nos legou através da confrontação das personagens femininas com o espaço em que estão inseridas, e da forma como dão expressão à sua sexualidade nesse mesmo espaço. Assim sendo, pode observar-se como funcionava o sertão, apossando-nos das palavras de Adair Neitzel:

O sertão impõe regras próprias de conduta àqueles que nele se propõem, e os valores preservados nele, a constituição familiar, a distribuição geográfica das fazendas, a vegetação e o relevo, a economia pecuária, bem como o mandonismo dos latifundiários, são elementos-chave na construção de Grande sertão: veredas. (2004, p. 15)

Neitzel refere-se ao Grande Sertão: Veredas, mas o mesmo se pode dizer do "Buriti," ou seja, neste também encontramos uma parte do sertão com suas próprias regras. A imperar e a estabelecer as regras do Buriti Bom temos a figura de iô Liodoro, o patriarca, que segundo o narrador "era homem punindo pelos bons costumes, com virtude estabelecida, mais forte que uma lei, na sisudez dos antigos. (...) prezava o inteiro estatuto de sua casa, como que não aceitando nem a ordem renovada, que para êle já podia parecer desordem" (ROSA, 1956, p. 95), e mais à frente, "lô Liodoro é um homem pelo direito, modas antigas" (p. 103), culminado em, "Êsse homem é um poder, êle é de ferro!" (p. 104).

O espaço desta fazenda sertaneja é um espaço controlado pela figura do patriarca, respeitado, detentor da lei e preservador das regras e costumes antigos. É, por assim dizer, um espaço conservador, em que a figura feminina de classe social superior devia ter controlo sobre a sua conduta e exposição em espaços ocupados pelos subalternos, arriscando-se, em contrário, a ser alvo das "máslínguas," como se observa nos comentários insistentes de nhô Gual. O espaço do sertão opõe-se à cidade, o que se encontra bem patente ao longo do conto: "Dizia da roça, da vida do sertão, que seria 
pura, imaginada simples e ditada de Deus, contra a vida da cidade" (p. 127). A cidade é vista como o lugar do devaneio, dos modos impróprios e liberais, da "regateirice" e "falta-de-pudor" (p. 104): "No que a cidade e o sertão não se dão entendimento: as regalias da vida, que as mesmas não são. Que aqui no sertão, um, ou uma, que muito goza, como que está fazendo traição aos outros” (p. 96). Atentemos, então, na forma como Maria da Glória e Leandra constroem a sua sexualidade num espaço que, em princípio, as limitaria.

A descrição que nos é dada, logo desde o início da narrativa, destas duas personagens femininas, aponta para características que as definem pelo lado da invulgaridade. Glorinha é vista como "uma onçazinha" (p. 86), "uma mulher que deve desnortear" (p. 88), além de que "era a bela, firme para governar um cavalo grande, montada à homem, com calças amarelas e botas, e a blusa rústica de pano pardo, ela ria claro e sacudia a cabeça, esparramando os cabelos, dados, em quantidade de sol. Galopava por tôda a parte, parecendo um rapaz" (p. 110). Quando Miguel a compara com a mãe afirma que "Maria da Glória era a mulher que menos me lembrava minha mãe. Ela não me lembrava pessoa alguma" (p. 128).

A descrição de Dona Lalinha, ou Leandra, carrega desde logo o estigma da diferença da mulher citadina:

Vê-se, é pessoa fina, criada e nascida em cidade maior, imagem de princesa. Cidade: é para se fazerem princesas. Sua feição-os sapatos, o vestido, as mãos, as unhas esmaltadas de carmesim, o perfume, o penteado. Tudo inesperado, tão absurdo, a gente não crê estar enxergando isto, aqui nas brenhas, na boca dos Gerais... Dona Lalinha não é de verdade. (p. 85)

Como se pode notar através destas descrições, tanto uma como outra, são mulheres que, de alguma forma, não se podem comparar a mais ninguém, além de que ambas são associadas a animais: Glória a uma "onça" e o nome Leandra, de origem grega, significa "leão," ou seja, ambas carregam em si algo de selvagem, animal e incontrolado. Destaca-se ainda o facto de Glória ser comparada nas suas maneiras a um rapaz, o que faz com que ela tenha uma força que normalmente é associada ao lado masculino.

Ao longo da narrativa começamos a observar que esta descrição de Glória e Lalinha não é de todo inocente, ela prepara-nos para acções protagonizadas pelas mesmas que, de outro modo, não seriam possíveis. Sabemos que, segundo as regras do sertão, Lalinha se devia confinar a uma posição de mulher casada, embora abandonada pelo marido, "Ainda que iô Irvino tenha repudiado a mulher, e esteja a viver com outra, Dona Lalinha tem de conservar sua solidão, não pode receber o prazer de outro homem" (p. 90), e que Glorinha, mesmo sendo "estudada," devia esperar por Miguel para se casar. Contudo, não é bem o que se passa. Estas duas personagens provocam nos homens um sentimento de medo, "Vi-a, a vulto, mas sentindo densamente sua presença... Logo não olhei; como não se olha o alagável do sol, digo, porque me travou um mêdo" (p. 128); de incompreensão, "As mulheres. Como delas Miguel mesmo reconhecia saber pouco" (p. 133); e preconceito, "Quando as mulheres assim se entendem, tão íntimas—se sabe-então seu instinto se tece, estão se estabelecendo contra o homem" (p. 133). Nesta medida, é necessário que o homem crie um espaço de repressão e controlo, uma vez que estas mulheres possuem uma feminilidade exagerada, ofuscante, além de terem "a idéia sem sossêgo (...)" (p. 120), o que representa uma ameaça ao poder masculino. De acordo com Molly Hite,

Too much of a good thing may be the worst thing of all from the perspective of a value system that aims above all to control manifestations of the feminine. In order to be product, object, or fetish, women must remain within boundaries ordained from outside, constricted to the dimensions that the dominant culture deems appropriate by devices ranging from exemplars to definitions to corsets. If this culture aligns the feminine with nature, spontaneity and contingency, it also aims to regulate these characteristics so that they stay within manageable dimensions. For a woman to possess them in excess is as dangerous to masculinist assumptions as for her not to possess them at all. (1988, p. 136)

Visto tanto Glória como Lalinha serem mulheres cuja personalidade e beleza excedem os limites do razoável, e consequentemente serem encaradas como um perigo para os homens, a 
solução proposta por estes é, então, estabelecer regras de domínio, sendo que algumas destas se configuram no estabelecimento de fronteiras espaciais. Nesta medida, pensam poder controlá-las. É o que sugere o comentário de Gualberto acerca da fragilidade de lô Liodoro quando se trata das filhas: "Só que, o povo acha que êle não devia consentir em Maria da Glória com tanto arvoamento, gineteando sòzinha pelos campos, e não se pejando de querer companhia de homem, para conversação. . . É pelos costumes" (p. 121-22).

$\mathrm{Na}$ continuação da narrativa, ambas as personagens femininas movem-se livremente pelo espaço fora da casa, sendo um dos seus espaços preferidos, o Buriti, ou seja, uma árvore que além de na obra ter conotações fálicas, as expõe em espaço aberto ao olhar do masculino. Além da transgressão de espaços, Glória e Lalinha infringem também as normas da heterossexualidade, aquando da expressiva sugestão de homossexualidade em mais de uma situação na narrativa:

Pudesse, estaria deitada junto de Maria da Glória, queria que Maria da Glória, horas sem tempo, a abraçasse e beijasse, Ihe desse todos os afagos, como se ela, Lalinha, Lala, fôsse uma menina, um bichinho, diminuindo, cada vez mais diminuindo, até meio menos não existir, e dormir-só um centro. Dividiuse... (165)

Glorinha pagava-se para outras perguntas, cuidando-a de repente com ativo carinho, achava-lhe frios os pés, ajeitava-lhe 0 cobertor:- "Até os pés você tem tão lindos, Lala..." Era bom, o bom calor das mãos moças palpado-lhe de leve o pé, sob o oculto das coberturas, ela se impediu de qualquer protesto, do menor estremecimento. (p. 199)

O que é excecional nestas passagens é que as duas personagens veem o prazer feminino como uma opção, onde o desejo feminino não coincide exatamente com o desejo masculino ou seja, o desejo de homens que as encaram como objetos de prazer sexual ao se focalizarem nos seus atributos físicos, como é o caso de nhô Gual e Miguel. Segundo Susan Winnett,

women's pleasure can be extraneous to that culmination of heterosexual desire which is copulation. Women's pleasure can take place outside, or independent of, the male economy whose pulsations determine the dominant culture, its repressions, its taboos, and its narratives, as well as the "human sciences" developed to explain them. (1990, p. 505)

Embora a narrativa não culmine numa expressão de homossexualidade, bem pelo contrário, ela é exime em mostrar que a sexualidade não é algo de cem por cento definido, além de evidenciar o direito da mulher sobre o controlo do seu corpo.

Lalinha e Glória estão ambas conscientes do seu corpo e do poder que este exerce sobre os homens ao suscitarem-Ihes o desejo sexual: "Maria da Glória tinha suor e cuspe, como a bôca da gente se enche d'água e o corpo dêle, Miguel latejava..." (p. 144). Atente-se ainda na seguinte passagem, em que Glória se compraz em ser observada por Gualberto:

Maria da Glória pusera-o a dar corda na vitrola, e um tanto confuso êle obedecia. E, sim, agora Lalinha podia comprovar como êle, às furtas, mas desenvolvidamente, não tirava os olhos das pernas, das formas convidativas de Maria da Glória (...). E viu: porque se atordoava-era porque Maria da Glória reparadamente se comprazia com a nojenta admiração, dava mostras de instigá-la; era, estava sendo impudica. (p. 177; ênfase minha)

Várias são ainda as problemáticas que estas personagens colocam em termos de emancipação feminina. A título de exemplo, temos a questão da independência e liberdade: "Mas, então, iô Liodoro reputava-a uma menor, teimava em tê-la por issouma mulher sob sujeição?" (p. 149). São, igualmente, mulheres que não desassociam o amor carnal do espiritual, que desejam um amor realizado, que querem serem sujeitos numa relação na medida em que sentem que o seu corpo tem desejos e prazeres próprios: "Mesmo quando descobriu que, para a verdade do amor, era necessária a carne: que a carne dôesse, leve, devagar, enquanto ela murmurava sua intransmissível paixão, e prometia e implorável" (p. 153); "Mas, também outra espécie de amor devia poder um dia existir: o de criaturas conseguidas, realizadas" (154).

Embora Lala e Glória se projetem como mulheres emancipadas no mundo em que vivem, não podemos deixar de observar que têm também as suas limitações, uma vez que não são mais do que a construção desse mundo cultural, tecido por simbolismos onde o género é subjacente. De acordo 
com Richard G. Parker, "What particular individuals can or cannot imagine is shaped, as much as the sexual realm as in any other, by the intersubjective symbols and meanings of the world in which they live" (1991, p. 133). É neste sentido que estas personagens se encontram ainda limitadas por noções de pecado e pudor, pois, a sociedade em que se inserem é patriarcal, religiosa e embora a cidade seja mais liberal, ainda há resquícios de costumes e mentalidades antigos. A prova é Lalinha, que apesar de toda a sua emancipação de mulher da cidade, não deixa de revelar certos preconceitos:

Se não, porque aquele capricho no mudar de posição, de reclinar-se, tão santinha quieta, tão calma, cruzando as pernas, suspendendo mais a barra do vestido? Oh, aquilo horrorizava, parecia uma profanação bestial, parecia um estupro. A sério, iria ter uma conversa com ela, com a amiga, com a cunhada, aconselhá-la a cuidado, a não se expor assim. (p. 177)

O mesmo acontece com Glória: “-'Muita vez, de noite, quando fico desinquieta, levanto, ajoelho na beira da cama e rezo (...)"' (p. 157). No final da narrativa, esta noção de culpa e pecado atenuam-se e o que temos são duas mulheres cujos limites são inimagináveis.

Dois episódios do conto são fundamentais para se perceber a forma como estas mulheres se constituem como sujeitos. O primeiro, são os encontros de Lalinha com lô Liodoro. Estes acontecem na sala, ou seja, dentro de casa, clandestinamente. Uma vez que Lalinha ainda é considerada mulher casada, estes encontros com 0 sogro, que acabam por se consumar, são uma forma de adultério. Há, então, por parte da personagem feminina uma transgressão de normais sociais. Por outro lado, e de acordo com Tony Williams, "the home as kind of preserve of conjugal love, [sets] up invisible barriers to extramarital encounters" (2000, p. 40). Uma segunda transgressão é cometida, pois Lalinha transgride também o espaço físico da casa, o que culmina no efeito de "desacralising the home" (2000, p. 41).

Ao analisarmos mais pormenorizadamente os encontros entre Lalinha e lô Liodoro não pode deixar de haver dúvida que é ela quem comanda este jogo, um jogo em que o desejo aumenta progressivamente, tornando-se impossível mantê-lo através da linguagem, pois os corpos ardem e o contacto tornase quase inevitável. Leandra entra numa luta de forças com o patriarca, o homem, o macho: "Gostaria de poder certificar-se de todos os efeitos que sua sensível produzia no semblante, no corpo dêle, o macho. Um macho contido em seu ardor- era como se o visse por detrás de grades, ali sua virilidade podia inútil debater-se" (p. 215). Através do "poder do prazer," num jogo em que a linguagem incita ao desejo, Liodoro obedece cegamente a Leandra, sendo capaz de por ela transgredir as regras da sua casa: "Obedecia-Ihe-aquêle homem corpulento, poderoso,- -e penetrava àquela hora, em seu quarto-quase uma profanação! Ah, nunca êle saberia, por Deus, o estremecimento de desgarrante delícia que Ihe estava proporcionando" (p. 219).

Tendo em conta a argumentação de Tony Williams, "The bedroom is initially perceived as a secret space. It is rare for the lover to be found there (...) When the lover does make his way into the bedroom, it is as if he is trespassing on sacred ground (...)" (2000, p. 49). Lalinha consegue que este homem transgrida, por sua causa, espaços que Ihe estariam proibidos. Ela tem o poder da sedução através da linguagem e do domínio do seu corpo: "Mas, não, não poderia nela tocar" (p. 219). A forma natural como domina e conhece o seu corpo é a arma desta personagem, de forma que, quando é necessário ela consegue proporcionar prazer a si própria: "Ela podia amar-se, era bela, seus seios, o ardente corpo, suas lindas mãos de dedos longos. Sentia-se os lábios úmidos demasiado, molhados, como se tivesse beijado, como se tivesse sugado, e era uma seiva inconfessável. Depois, um deixo amargo, na bôca. Assim adormecia" (p. 219-20).

A dissimulação faz também parte deste jogo, em que Lalinha "se [fingia] de escrava" (p. 220), apenas para que Liodoro pense que é ele quem detém o poder. Este jogo erótico é, entretanto, interrompido pelo patriarca e Lalinha pensa que fracassou, chegando quase a desistir e voltar para a cidade. O inconformismo leva-a, no entanto, a dar o 
golpe fatal. As palavras de Leandra são diretas e prova de que ela é uma mulher decidida, que sabe o que quer, e que não olha a meios para o obter: "Você, escuta: sou livre, vou-me embora. Na cidade, vou ter homens, amantes... Você gosta de mim, me acha bonita, você me deseja muito, eu sei. Pois, se quiser, se vale a pena, estou aqui. Esta noite, deixo a porta do quarto aberta (...)" (p. 243).

Lalinha incita lô Liodoro à última e definitiva transgressão, uma vez que: "From the man's point of view, the bedroom is an impossible place, in which contradictory reactions are called for: respect for the virtue of the heroine, somehow more palpable in the bedroom, desire for consummation provoked by her undressed state" (WILLIAMS, 2000, p. 45). lô Liodoro sai vencido deste jogo ao passar a fronteira do quarto dela:

Lala fechou a janela. Tôda se preparara, de estudo. Agora se despia. Sim, ia esperá-lo desse jeito, sobre as roupas do leito, em carne. Sim, pouco somava com o friozinho, que a arrepiava um tanto. Seus seios. Mas, êle, se viesse, teria de achá-la assim, dizendo de vencido pudor, de desejo e liberdade.

(...)

Aí, de repente, resvés a porta se abria. Era êle-o vulto, o rosto, o espêsso- ocupava-a tôda. . . Respirava, e vinha, para conhecê-la. De propósito, Lala riu e disse-o mais trivial, o mais sábia que pôde, o mais soezmente:"Anda, você demorou. . . Temos de encher bem as horas (...)" (p. 244)

Atente-se, neste momento, em mais pormenor, nas acções de Glória. Da mesma forma que Lalinha, Glória abandona, igualmente, os seus pudores e liberta-se sexualmente através de uma relação com nhô Gual, em que o sentimento de culpa não existe: "Ele conseguiu tudo comigo (...). Que é que você tem? Eu não estou sã, não estou viva?! Ah... Agora, meu bem, não sou virgem mais: sou mulher, como você" (p. 241). Ao ter esta relação com Gual, Glória transgride, uma vez mais, o espaço, uma vez que esta relação se dá num espaço em que ela não deveria estar segundo as regras do patriarcado: "Foi num lugar escondido, bonito, no Alto-Grande (...)" (p. 242). O que não pode deixar de ser notado é que Glória, como mulher de classe superior a Gual e, portanto, não devendo ter relações estreitas com ele, ao manter uma relação sexual com este homem, transgride não só a fronteira entre espaço masculino/feminino, como a fronteira subalterno/proprietário. É interessante ainda verificar que nesta relação é Glória que também detém o poder e o controlo: "-Não, Lala. Fui eu que mandei. Quase que o obriguei a fazer tudo, a perder o respeito, que êle tinha demais (...)" (p. 242).

Através das ações transgressoras das duas personagens femininas, a casa, e a sociedade patriarcal que esta representa, sofrem uma mudança no sentido da igualdade da mulher. Nem uma, nem outra personagem feminina morrem, nem sofrem nenhuma consequência pelos seus atos. Há um mundo novo à espreita, é como se através de Glória e Lalinha "o mundo tivesse de ser aprendido de novo, de momento para outro alargado na claridade de uma extensão, que alterava o passado" (p. 241). Quando o narrador afirma que "O Buriti Bom era Maria da Glória, dona Lalinha" (p. 250), aponta para uma nova ordem, uma ordem na qual o feminino tem um corpo e uma voz.

\section{Dois autores, duas visões do feminino}

Do que ficou exposto neste estudo podemos extrair alguns comentários finais. Graciliano Ramos e Guimarães Rosa assemelham-se num aspeto particular que se configura no facto de ambos nos proporcionarem uma visão da mulher que já não se encontra de modo algum associada a termos como passividade, dependência, subjugação ao ser masculino. Contudo, quando observamos Madalena, embora ela seja o motivo de uma tentativa de mudança por parte de Paulo Honório, e a sua personalidade demonstre independência e insubordinação, ela é-nos revelada apenas através de um olhar masculino que teve de provocar a sua morte para que ele próprio pudesse sobreviver. Deste modo, Madalena teve de encontrar um outro espaço e pagou o preço por ter transgredido as regras de um sistema patriarcal. Ressalta-se, igualmente, o facto de esta personagem feminina não ter conseguido constituir-se como sujeito, possuidor de uma sexualidade, nesse espaço; este narrador não nos 
transmite nenhuma informação sobre desejo e prazer sexual em relação a Madalena. Ela constitui-se, no entanto, como figura essencial ao questionar, como se viu, as fronteiras não apenas entre o espaço masculino/feminino, como também entre subalternos/fazendeiros.

Quando se passa para o universo feminino rosiano, deparamo-nos com uma situação extremamente complexa, em que a conclusão é sempre indefinida, incerta e insegura. Talvez, como a sua própria linguagem, Guimarães Rosa pretendesse revelar-nos que o género é algo que deve ser encarado duplamente num sentido universal, mas ao mesmo tempo, num sentido muito particular, em que cada pessoa é um caso e esse caso pode abranger várias camadas. Se os sentimentos mudam, também as inclinações podem mudar. Tal como o sertão é um mundo, cada pessoa também o é.

No entanto, tendo em conta o estudo aqui desenvolvido que teve como foco principal a análise do espaço em que Glória e Leandra se desenvolvem e constituem, pode observar-se que existe um salto em relação à obra de Graciliano Ramos. Por um lado, o narrador utilizado por Guimarães Rosa é, tal como as suas personagens, bastante mais complexo; nunca se sabe ao certo se é sempre Miguel quem narra esta história, sobressaindo o facto de este narrador ser capaz de nos transmitir o íntimo das personagens femininas em primeira pessoa, nomeadamente no caso de Leandra. Por outro lado, em Rosa há a possibilidade de estas mulheres se constituírem como sujeitos, elas transgridem espaços e normas sociais-como é o caso de Glória, que põe em causa as fronteiras de relações entre mulher de classe superior e subalternos quando mantém uma relação sexual com Gual-mas não pagam nenhum preço, muito pelo contrário, elas saem realizadas tanto socialmente como sexualmente. O que é excecional em Guimarães Rosa é que na sua narrativa há a opção de afirmação do prazer feminino, podendo este coincidir ou não com o desejo masculino.

\section{Referências}

ABREU, Maria Isabel. "O Protesto Social na Obra de Graciliano Ramos.” Hispânia 48 (1965): 850-855.

ARAÚJO, Heloisa Vilhena de. A Raiz da Alma. Corpo de Baile. São Paulo: Edusp, 1992.

ENGLEKIRK, Allan. "The Destruction of Realism in Short Prose Fiction of João Guimarães Rosa." South Atlantic Review 47 (1982): 51-61.

GINSBURG, Michal Peled. "Vision and Language: Teaching Madame Bovary in a Course on the Novel." Approaches to Teaching Flaubert's Madame Bovary. Ed. Laurence M. Porter and Eugene F. Gray. New York: MLA, 1995. 61-68.

GRAHAM, Sandra Lauderdale. House and Street. The Domestic World of Servants and Masters in Nineteenth- Century Rio de Janeiro. Cambridge: Cambridge UP, 1988.

HELENA, Lúcia. "A personagem feminina na ficção brasileira nos anos 70 e 80: Problemas teóricos e históricos." Luso-Brazilian Review 26 (1989): 4357.

HITE, Molly. "Writing-and Reading-the Body: Female Sexuality and Recent Feminist Fiction." Feminist Studies 14 (1988): 120-142.

KEATING, Elizabeth. "Space." Journal of Linguistic Antropology 9 (1-2): 234-237.

MAZZARA, Richard A. "New Perspectives on Graciliano Ramos." Luso-Brazilian Review 5 (1968): 93-100.

McDOWELL, Linda. Gender, Identity and Place. Understanding Feminist Geographies. Minneapolis: UMP, 1999.

NEITZEL, Adair de Aguiar. Mulheres rosianas. Percursos pelo Grande sertão: veredas. Florianópolis: UFSC, 2004.

NETO, Godofredo de Oliveira. A Ficção na Realidade em São Bernardo. Belo Horizonte: Nova Safra, 1990.

PARKER, Richard G. Bodies, Pleasures and Passions. Sexual Cultural in Contemporary Brazil. Boston: Beacon Press, 1991.

RAMOS, Graciliano. São Bernardo. Mira-Sintra: Publicações Europa-América, n/d.

ROSA, João Guimarães. Corpo de Baile. Vol 2. Rio de Janeiro: José Olympio, 1956.

SANTOS, Wendel. A Construção do Romance em Guimarães Rosa. São Paulo: Ática, 1978. 
SHELL, Marc. Money, Language, and Thought. Baltimore and London: The Johns Hopkins UP, 1993.

SOVEREIGN, Marie F. "Pessimism in Graciliano Ramos." Luso-Brazilian Review 7 (1970): 57-63.

SULEIMAN, Susan Rubin. "(Re)Writing the Body: The Politics and Poetics of Female Eroticism." Poetics Today 6 (1985): 43-65.

VIANNA, Lúcia Helena. Roteiro de Leitura: São Bernardo de Graciliano Ramos. São Paulo: Ática, 1997.
VINCENT, Jon S. "Corpo de Baile." Luso-Brazilian Review 14 (1977): 97-117.

WILLIAMS, Tony. "Threshold of Desire and Domestic Space in Nineteeth-Century Franch Fiction." Secret Spaces, Forbidden Places. Ed. Fran Lloyd and Catherine O'Brien. New York: Berghahn Books, 2000. 39-49.

WINNETT, Susan. "Coming Unstrung: Women, Men, Narrative, and Principles of Pleasure." PMLA 105 (1990): 505-518.

\section{COMO CITAR ESSE ARTIGO}

SOUSA, Sandra. Quando as mulheres transgridem o espaço: João Guimarães Rosa e Graciliano Ramos em comparação. Signo, Santa Cruz do Sul, v. 42, n. 74, maio 2017. ISSN 1982-2014. Disponível em: $<$ https://online.unisc.br/seer/index.php/signo/article/view/8369>. Acesso em: doi: http://dx.doi.org/10.17058/signo.v42i74.8369. 